\title{
Improved understanding and satisfaction with a modified informed consent document: a randomized study
}

This article was published in the following Dove Press journal:

Patient Intelligence

7 May 2012

Number of times this article has been viewed

\author{
Peter C Raich ${ }^{1,2}$ \\ Ralph L Kennedy' \\ Chris Vanoni' \\ William Thorland ${ }^{2}$ \\ Naamon Owens' \\ Charles L Bennett ${ }^{3}$ \\ 'AMC Cancer Research \\ Center, University of Colorado \\ Comprehensive Cancer Center, \\ Denver, ${ }^{2}$ Denver Health Medical \\ Center, Denver, Colorado, USA: \\ ${ }^{3}$ Center for Management of Complex \\ Chronic Care, Hines Veterans \\ Administration Hospital, Hines, \\ IL, USA
}

Correspondence: Peter C Raich

University of Colorado Denver, Division of Hematology/Oncology, Denver Health Medical Center, 777 Bannock Street, MC 400I, Denver, CO 80204, USA

Tel +l 3036026062

Fax +l 3036026067

Email peter.raich@dhha.org
Background: Informed consent documents need to convey crucial information to prospective study participants. We assessed the impact of an informed consent process designed to be understood by persons with low health literacy skills.

Methods: We conducted a randomized controlled trial with ethnically and racially diverse male veterans. Participants were randomly assigned to receive and read the standard consent document for the Selenium and Vitamin E Cancer Prevention Trial prostate cancer prevention trial or a culturally tailored, easy-to-read consent document. Telephone interviews were conducted 2 weeks following consent, assessing comprehension, satisfaction, consent anxiety, state anxiety, decisional conflict, and cultural sensitivity.

Results: Of 162 male veterans completing the initial telephone interview, 49.7\% were African American, $44.1 \%$ were Caucasian, and $6.2 \%$ were Hispanic. The mean comprehension score for the consent document and process was significantly increased in the intervention arm participants (17.08) versus the standard consent arm $(15.06, P<0.0001)$. The satisfaction score with the consent information was higher in participants in the intervention arm (3.67 vs 3.42, $P=0.0009)$, while the consent anxiety score was reduced ( 1.31 vs $1.56, P=0.0067)$.

Conclusion: Modifications in the reading level, format, appearance, interactivity, and cultural sensitivity of an informed consent document in the cancer prevention setting significantly improved comprehension of and satisfaction with the consent document, while decreasing consent anxiety.

Keywords: health literacy, informed consent, clinical trial

\section{Introduction}

The informed consent document and the consent process are integral parts of clinical research. Consent documents must provide information about the details of the study and allow prospective participants to weigh potential risks and benefits, taking into account personal beliefs, values, and expectations. Truly informed consent implies that the participant understands the essence of the study, as well as his or her rights and responsibilities within the framework of the study and the medical care system. ${ }^{1}$ There is ample literature on the poor and incomplete comprehension of information provided to study participants. ${ }^{1-4}$ Consent documents continue to be written at reading levels considerably above those of the majority of the US population. In 1993, Kirsch et $\mathrm{al}^{5}$ reported on the status of adult literacy in the USA, concluding that approximately $50 \%$ of the adult population of the USA function at or below an 8th grade reading level, and $25 \%$ are in the lowest literacy group, functioning at or below a 5 th grade level. A more recent repeat national adult literacy survey, 10 years after the first, unfortunately found 
no improvement; in fact, the results showed poorer levels of functioning in some minority populations. ${ }^{6}$

In 1999, the Institute of Medicine report The Unequal Burden of Cancer $^{7}$ identified poorly understood consent documents as a major barrier to the recruitment of minorities and other medically underserved populations. With the introduction of the National Cancer Institute informed consent template and recommendations, ${ }^{8}$ the format and understandability of informed consent documents have improved but are still at or above 10th grade reading levels. ${ }^{9}$ This does little to engage the prospective participant in utilizing the consent document as a learning and decision-making tool. ${ }^{1}$ In our earlier study on the modification of the consent document, ${ }^{10}$ we reduced the reading level in the document from the 12 th to 7 th grade, in addition to improving the layout, style, and font size. In the setting of several breast and lung cancer cooperative group clinical trials, we were able to show that these modifications improved satisfaction with the consent document $(P=0.004)$ and reduced consent anxiety $(P=0.016)$. This prior study and the Institute of Medicine report focused on clinical trials involving patients with cancer. Persons with poor health literacy skills, who are potential participants for cancer screening and prevention trials, face additional barriers to understanding informed consent documents. These individuals often have poor understanding of the clinical issues associated with cancer screening and prevention and little exposure to relevant background material. We previously reported that a modified informed consent process tailored to persons with poor health literacy skills facilitated patient accrual to a colorectal cancer screening trial among older veterans. $^{11}$

In the present study, we extend our prior work and evaluate the feasibility of incorporating tailored information into the consent process when approaching veterans about potential involvement in a cancer prevention clinical trial. The modified consent form was written at a 6 th grade reading level. The document also incorporated questions and answers to emphasize key information, included graphics to engage the reader, specifically addressed cultural appropriateness and sensitivity, and included a supplemental informational videotape. We assessed the impact of these modifications to the informed consent process for the National Cancer Institute/Department of Veterans Affairs cosponsored Selenium and Vitamin E Cancer Prevention Trial (SELECT) ${ }^{12}$ in a randomized study conducted on a veteran population. Major outcomes, reported here, include differences in comprehension, participant satisfaction, decisional anxiety, and decisional conflict associated with the consent documents.

\section{Methods}

\section{Study participants}

Prospective participants were recruited through local, regional, and national veterans' organizations, at American Legion state and national conventions, as well as at regional Vet Centers, American Legion posts, and Veteran Services Offices. Veterans were informed that they were not enrolling in the SELECT trial but into a study about the SELECT informed consent statement. In addition to their veteran status, eligibility for participation in the consent study was the same as for SELECT: males aged 55 years or older - 50 or older if African American conversant and able to read in English and sign the consent documents, and able to be reached by telephone.

\section{Study design and procedures}

This study was a randomized controlled trial conducted from February 2004 to March 2005, comparing the standard consent document for the SELECT prostate cancer prevention trial with the modified version given to veteran participants. This study was initially designed to run concurrently with SELECT and refer patients to SELECT. However, due to the early closing of SELECT (the accrual rate was markedly faster than had been anticipated), our consent study was conducted with SELECT-eligible participants. Our participants were informed that the actual SELECT had recently completed its accrual. The study design and accrual numbers are depicted in Figure 1. After obtaining informed consent, the study coordinator assigned participants to either of the two arms by sequentially selecting envelopes containing the individual assignments as generated by a random number sequence. Participants were asked to read and review either the Veteran Affairs (VA) standard consent document or the modified consent document and brief introductory video. ${ }^{13}$ For both groups, telephone interviews were conducted at 2 weeks by trained interviewers through the AMC Cancer Research Center's Computer Assisted Telephone Interview (CATI) Unit. A 2-week period to allow participants to carefully read the consent document was felt to be appropriate for a cancer prevention trial. The study and the two versions of the consent documents were approved by the Institutional Review Boards of the American Medical Center (AMC) Cancer Research Center and the University of Colorado Health Sciences Center in Denver, Colorado. All participants provided written informed consent before enrollment into the study.

The primary hypothesis for the study was that the use of a modified consent document designed to be better understood by individuals with lower literacy skills 


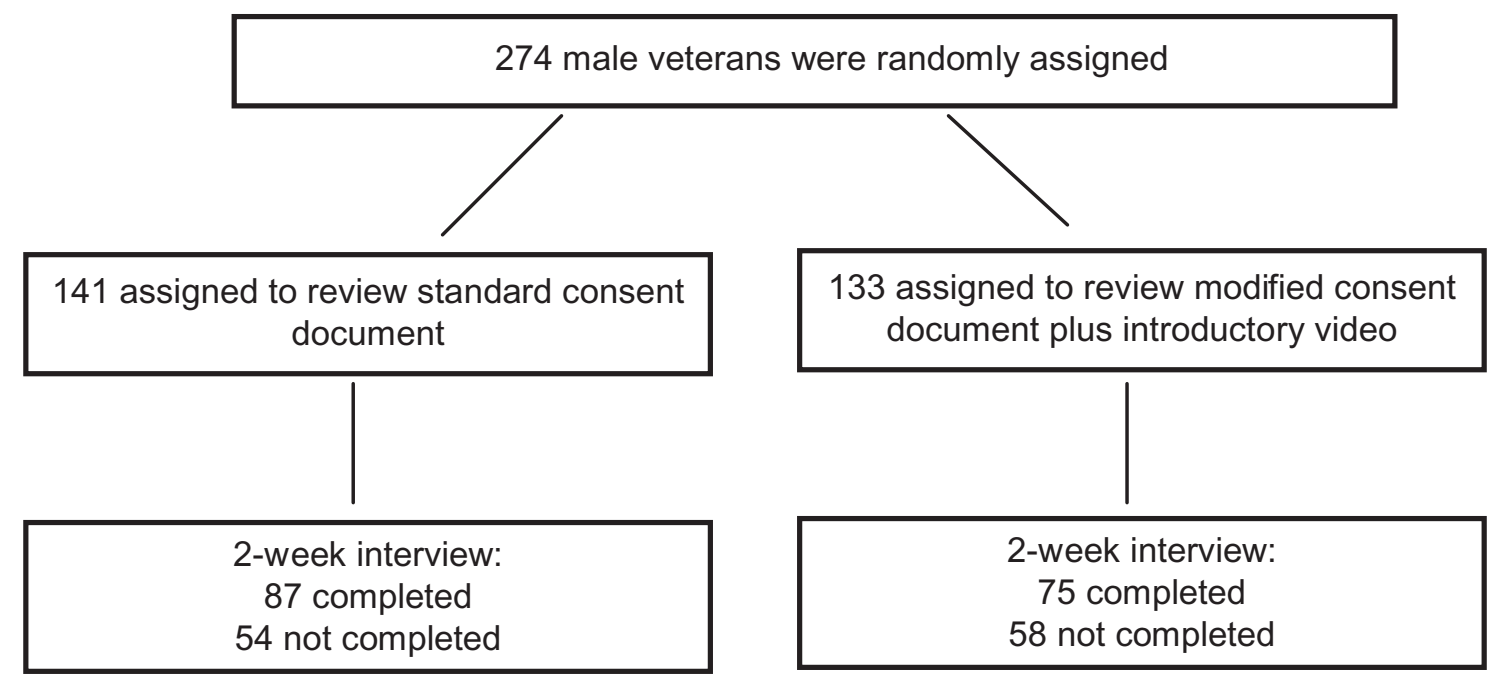

Figure I CONSORT flow diagram of study participants. Abbreviation: CONSORT, Consolidated Standards of Reporting Trials.

in a culturally sensitive manner, when compared with a standard consent document, would result in: better understanding of the purpose and conduct of the study, improved satisfaction with the consent process, and lower anxiety with the decision-making process. We further hypothesized that understanding would be positively impacted by higher REALM scores and lower state anxiety; satisfaction be positively impacted by greater understanding, lower consent anxiety and lower decisional conflict; and that consent anxiety be benefited by increased social support, higher REALM Scores, and lower decisional conflict. Our secondary hypothesis was that the use of the modified consent document would lead to a greater number of candidates willing to participate in the SELECT study.

\section{Assessment of primary and secondary endpoints}

The modified consent document, the telephone interviews, and the measures contained therein were pilot-tested prior to the main randomized study in 14 SELECT-eligible individuals. For the main study, once a participant signed the consent study's consent document, literacy was assessed using the Rapid Estimate of Adult Literacy in Medicine (REALM). ${ }^{14}$ During the telephone interview at 2 weeks, assessment included comprehension, satisfaction, consent anxiety, state anxiety, decisional conflict, cultural sensitivity, and intent to participate in SELECT.

Participant comprehension of the consent process and the SELECT study design and purpose was assessed with 22 true/ false and multiple-choice questions. These were not meant to be exhaustive but covered the major consent elements of privacy, study design, side effects, benefits, randomization, and cultural sensitivity. Content validity for this measure was high, as evidenced by the judgments of a panel of experts who reviewed the questionnaire, as well as the initial pilot testing. Patient satisfaction with the ease of reading and understanding the consent document was assessed using five items that had been developed for our prior study. ${ }^{10}$ This scale had high internal consistency as measured by Cronbach's coefficient alpha $(\alpha=0.85)$, with scale scores ranging from 1 (low satisfaction) to 4 (high satisfaction). Similarly, the consent anxiety measure was developed for our prior study. ${ }^{10}$ It included four items tailored to the specific aspects of distress correlated with giving consent for a study. Scores range from 1 (low consent anxiety) to 4 (high consent anxiety). Cronbach's coefficient alpha $(\alpha=0.82)$ indicated that the scale had high internal consistency. Patient state anxiety was assessed using the state subscale of the State-Trait Anxiety Inventory (STAI). ${ }^{15}$ Decisional conflict by the participant was measured by the Decisional Conflict Scale developed by O'Connor. ${ }^{16}$ This scale is a 13-question measure with scores ranging from 1 (high decisional conflict) to 5 (low decisional conflict). Social support was measured using Cohen et al's Interpersonal Support Evaluation List (ISEL). ${ }^{17}$ All participants were asked about their decision to participate (yes/no/undecided) in SELECT.

\section{Description of consent documents}

The standard consent document used in this study was the SELECT consent document, which was institutional review board-approved for use at the Denver VA Medical Center. Its reading level tested at the 7.9 grade level with the Flesch Grade 
Level Formula. ${ }^{18}$ Revisions to the modified version of the SELECT consent document included alterations in text style, page layout, font size, vocabulary, the addition of graphics, increased interactivity by interspersing questions and answers, and emphasis on cultural sensitivity. The content of the information provided was not altered. The modified consent document tested at the 5.6 grade level with the Flesch Grade Level Formula. Design elements of the modified consent document were evaluated according to the Suitability Assessment of Materials criteria by Doak et al. ${ }^{19}$ A question and answer format was used to organize the information. The page layout incorporated increased white space that complemented the use of added graphics and supplemental questions. The reading level of the modified consent statement was further enhanced by reducing the number of polysyllable words and multiple sentence paragraphs, using parallel sentence structure, representation of one idea per paragraph, and the use of personal rather than impersonal pronouns. While these enhancements resulted in a considerably longer document (increasing from 8 to 18 pages), participants were actually more satisfied with the modified form and did not find it excessively long. Cultural sensitivity assessment of the two consent documents was performed by a seven-member advisory/evaluation committee utilizing the Cultural Sensitivity Assessment Tool by Guidry and Walker. ${ }^{20}$ The committee members overwhelmingly rated the modified consent document, but not the standard consent document, as culturally competent, based on its format and written and visual messages. A copy of the modified version of the consent document is provided in the Appendix.

Each subject in the intervention group viewed an 8-minute supplemental videotape that described the SELECT study through an informal discussion by several veterans, who weighed their perceived risks, benefits, and decisional processes for participating in the SELECT study.

\section{Statistical analysis}

The analysis focused on eight short-term study endpoints. The power analysis was calculated for the primary endpoint of comprehension, measured on a 22-point scale. Using a twosided $t$-test, we estimated that 75 subjects in each group would be sufficient to show a significant difference in comprehension, with an alpha of 0.05 and power of 0.90 . The data were analyzed using $\mathrm{SAS}^{\circledR}$ statistical software (v 9.1; SAS Institute, Cary, NC). Differences between the standard and modified consent groups for continuous variables, test scores, and test subscales were analyzed by $t$-tests. In cases where the group variances were not statistically different, a pooled variance was used; otherwise, a modified Satterthwaite correction was used. Pearson chi-square tests were employed to determine $P$ values for differences between the standard and modified groups for categorical variables.

Multiple linear regression analysis was used to control for the effects of moderators as confounders. In a series of analyses, the type of consent form was treated as an independent variable and assessed for the significance of its relationship with each of the primary dependent variables (comprehension, consent anxiety, satisfaction, or decisional conflict), as well as the seven subscales of comprehension (privacy, treatment protocol, side effects, randomization, benefit to others, personal benefit and diversity awareness). In each of these regression models, the potential moderators (age, White, non-white, REALM score, self-efficacy, ISEL-total, ISEL-appraisal, ISEL-tangible, ISEL-belonging, state anxiety, consent anxiety, decisional conflict, perceived barriers, attitude, and satisfaction) were also treated as independent variables in forward stepping analyses. Inclusion criteria for variables was set at $P<$ or $=0.05$ and removal criteria was set at $P>$ or $=0.10$.

\section{Results \\ Study population characteristics}

Subjects were recruited from February 2004 to March 2005 . The 274 initially eligible subjects were randomized to receive either the standard $(n=141)$ or the modified SELECT consent statement $(n=133)$ (Figure 1). Two-week telephone interviews were completed with 162 (59\%) of these subjects. The major reasons for inability to complete the interviews in both groups included nonworking telephone numbers, unanswered calls, language barriers, opt-out at the subject's request, or arrival at the maximum number of contact attempts. The slightly unequal numbers in the initial randomization were due to chance selection.

Of 162 male veteran participants completing the initial telephone interview, 49.7\% were African American, 44.1\% were Caucasian, and $6.2 \%$ were Hispanic. Table 1 compares the characteristics of the control and intervention participants. The composition of each group was well balanced with regard to age, REALM scores, and state anxiety scores. As shown in Figure 2, the distribution of REALM scores differed somewhat among the three racial/ethnic groups, with African American men and Hispanic men showing a higher percentage of scores in the low and medium literacy ranges.

\section{Intervention effects}

The effects of the intervention on major outcome variables are summarized in Table 2. Comprehension was significantly 


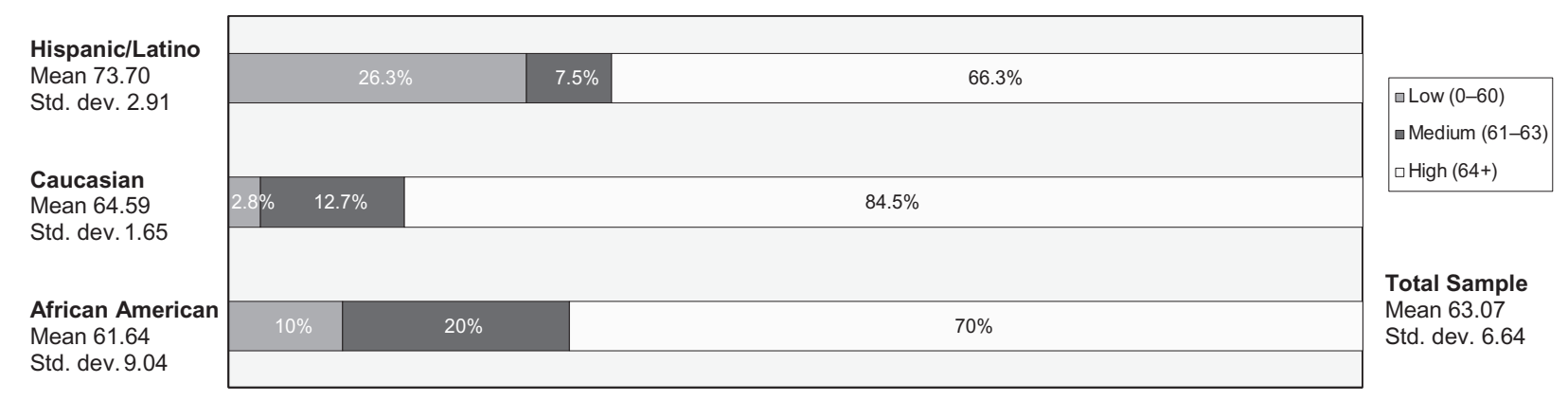

Figure 2 Distribution of REALM scores among the three racial groups.

Note: Horizontal scale is in percent.

Abbreviations: REALM, Rapid Estimate of Adult Literacy in Medicine; Std. dev., standard deviation.

increased in participants using the modified (easy-to-read) version of the SELECT consent document rather than the standard consent form $(P<0.0001)$. Comprehension was positively affected by higher REALM score $(P=0.013)$ and marginally by Caucasian race $(P=0.05)$, but not by STAI score $(P=0.4)$. Table 3 shows the distribution of mean scores among the standard and modified consent groups for each content category addressed in the consent statement. Scores for questions about the study protocol and side effects showed the greatest improvement in the modified consent group, with privacy and diversity issues showing borderline improved scores.

Also shown in Table 2, satisfaction was significantly increased in participants using the modified compared rather than the standard consent document $(P=0.0009)$. Satisfaction was positively affected by low decisional conflict $(P<0.0001)$, low consent anxiety $(P=0.0001)$, and low STAI score $(P=0.0008)$. It was marginally affected by increased comprehension $(P=0.05)$, but not by REALM score $(P=0.20)$.

Consent anxiety was significantly decreased in participants using the modified rather than the standard consent document

Table I Characteristics of study population

\begin{tabular}{|c|c|c|c|}
\hline $\begin{array}{l}\text { Subject } \\
\text { characteristics }\end{array}$ & $\begin{array}{l}\text { Standard form } \\
(\mathrm{n}=\mathbf{8 7}) \\
( \pm \text { std. } \text { dev. })\end{array}$ & $\begin{array}{l}\text { Modified form } \\
(n=75) \\
( \pm \text { std. } \text { dev. })\end{array}$ & $P$ value \\
\hline Age, mean & $61.3( \pm 6.34)$ & $60.6( \pm 6.30)$ & $\begin{array}{l}0.55 \mathrm{I} \\
(t \text {-test) }\end{array}$ \\
\hline Race, \% African & $44.8 \%$ & $55.3 \%$ & 0.405 \\
\hline American & & & ( $3 \times 2$ chi sq. $)$ \\
\hline Race, \% Caucasian & $48.2 \%$ & $39.5 \%$ & \\
\hline Race, \% Hispanic & $7.06 \%$ & $5.3 \%$ & \\
\hline $\begin{array}{l}\text { REALM score, } \\
\text { mean }\end{array}$ & $63.3( \pm 4.65)$ & $63.6( \pm 4.08)$ & 0.912 (t-test) \\
\hline $\begin{array}{l}\text { State anxiety score } \\
\text { (Mean of I7 items) }\end{array}$ & $2.26( \pm 0.3 \mathrm{I})$ & $\begin{array}{l}2.25( \pm 0.29) \\
P=0.8\end{array}$ & $\begin{array}{l}0.833 \\
(t \text {-test })\end{array}$ \\
\hline
\end{tabular}

Abbreviations: Std. dev, standard deviation; chi sq., Pearson Chi-Square test; REALM, Rapid Estimate of Adult Literacy in Medicine.
$(P=0.007)$. Consent anxiety was positively influenced by greater social support (ISEL and all subscales, $P=0.0009$ ), higher REALM score $(P=0.004)$, and younger age $(P=0.01)$.

Other outcomes were affected as follows: Decisional conflict was not significantly decreased in participants using the modified consent $(P=0.17)$. It was positively impacted by low STAI score, high social support (ISEL and all subscales, $P<0.0001)$, and by higher REALM score $(P=0.002)$. State anxiety mean scores were identical in the standard versus the modified consent group. They were influenced positively by consent anxiety, ISEL and its subscales and age (all at $P<0.0001)$, and REALM score $(P=0.0004)$. Intention to participate was assessed at 2 weeks and showed a $6 \%$ difference in intention to participate (78\% in the modified group vs $72 \%$ in the control group, $P=0.4)$. Intention to participate was not affected by any outcome variable or moderator, including type of consent form $(P=0.38)$ or REALM score $(P=0.80)$.

Table 4 summarizes the independent variables selected as being significantly related to the dependent variables noted above. In the table, standardized beta coefficients and corresponding $\mathrm{p}$-values characterize the adjusted relative strength of the selected variables in their relationship with the dependent variable. Partial correlations are also shown, similarly reflecting such relationships. Among the primary dependent variables, the results of the multiple linear regression models confirmed the findings shown in Table 2 in that the type of consent form was significantly related to the outcomes of comprehension, satisfaction and consent anxiety, even as the effects of a number of other significant moderators were accounted for. Similarly, the type of consent form was once again shown as being not related to decisional conflict.

Among the sub-scales of comprehension, the multiple linear regression models also confirmed the findings shown in Table 3. With accounting of the effects of 
Table 2 Comparison of outcome variables

\begin{tabular}{llll}
\hline Major outcomes & $\begin{array}{l}\text { Standard form }(\mathbf{n}=\mathbf{8 7}) \\
\text { Mean }( \pm \text { std. dev. })\end{array}$ & $\begin{array}{l}\text { Modified form }(\mathbf{n}=\mathbf{7 5}) \\
\text { Mean }( \pm \text { std. dev. })\end{array}$ \\
\hline Comprehension score & 15.06 & 17.08 \\
(Number of correct responses out of 22 items) & $( \pm 3.63)$ & $( \pm 2.61)$ \\
Satisfaction score & 3.42 & 3.67 \\
(Mean of 5 items) & $( \pm 0.50)$ & $( \pm 0.42)$ \\
Consent anxiety score & 1.56 & 1.31 \\
(Mean of 4 items) & $( \pm 0.65)$ & $( \pm 0.46)$ \\
Decisional conflict score & 4.07 & 4.16 \\
(Mean of I2 items) & $( \pm 0.45)$ & $( \pm 0.45)$ & 0.0009 \\
\hline
\end{tabular}

Abbreviation: Std. dev., standard deviation.

potential moderators, type of consent form was shown to be significantly related to outcomes privacy, study protocol and side effects, but not to randomization, benefit to others, personal benefit, or diversity awareness.

\section{Discussion}

By using a modified consent document in the setting of a cancer prevention trial in a population composed of $55 \%$ minority men, we document a highly significant increase in both understanding and satisfaction, as well as a decrease in anxiety associated with the consent process. Understanding of the informed consent content was especially improved in the areas of study protocol, side effects, and privacy. Several factors should be considered in the interpretation of our findings.

Information dissemination processes tailored to lowliteracy populations should improve both satisfaction with the information exchange and understanding of the relevant information. In a previous intervention that evaluated a CD-ROM based interactive video that had not been tailored to low-literacy populations, veterans with prostate cancer indicated that they were very satisfied with the material, but comprehended very little of the information. ${ }^{21}$ We also previously reported that use of an easy-to-read informed consent document resulted in improved satisfaction and reduction in anxiety associated with the consent process in patients being recruited to cancer treatment trials, but comprehension was not improved. ${ }^{10}$ An earlier study by Davis et $\mathrm{al}^{22}$ reported similar results. However, the study materials in these trials were targeted at a 7 th-8th grade level. Building on these results, we reduced the reading level of the informed consent document to a 6th grade level and added graphics to complement this information, increased interactivity by interspersing questions and answers highlighting important concepts, addressed culturally sensitive issues using the Cultural Sensitivity Assessment Tool, ${ }^{20}$ and added a brief video depicting culturally diverse veterans discussing the pros and cons of participating in the SELECT study.

We were especially interested in testing these enhancements to the consent document in the setting of a large national prevention trial and with a diverse population of veterans. In our earlier consent study in the setting of cancer treatment trials, patient decisions were often driven by the need to make rapid treatment choices, a setting less likely to allow for careful deliberation and weighing of choices. In contrast, cancer prevention studies involve preferencesensitive decisions by prospective participants. ${ }^{23}$ These types of decisions make it especially imperative that the participant fully understand the potential benefits, or lack thereof, and any known and potential side effects. Furthermore, this decision is more likely to be influenced by participant

Table 3 Comprehension categories

\begin{tabular}{lllll}
\hline Content category & $\begin{array}{l}\text { Standard form }(\mathbf{n}=\mathbf{8 7}) \\
\text { Mean score (\%) }\end{array}$ & $\begin{array}{l}\text { Modified form }(\mathbf{n}=\mathbf{7 5}) \\
\text { Mean score }(\%)\end{array}$ & Difference \\
\hline Privacy & 50.6 & 60.0 & -9.3 & 0.055 \\
Protocol & 59.5 & 75.9 & -16.4 & $<0.0001$ \\
Side effects & 74.9 & 88.2 & -13.3 & 0.0005 \\
Randomization & 71.8 & 77.6 & -5.9 & 0.165 \\
Benefit to others & 86.1 & 86.8 & -0.7 & 0.797 \\
Personal benefit & 75.3 & 68.4 & 6.9 & 0.335 \\
Diversity & 42.4 & 56.6 & -14.2 & 0.072 \\
Overall & 68.0 & 83.0 & -5 & $<0.0001$ \\
\hline
\end{tabular}


Table 4 Regresssion analysis of the relation of type of consent form to principal dependent measures and the influence of other independent measures

\begin{tabular}{lllll}
\hline Dependent measure & Independent measures & Standardized beta & $\boldsymbol{P}$ & Partial correlation \\
\hline Comprehension & Type of consent form & 0.339 & 0.000009 & 0.348 \\
& Caucasian/non-Caucasian & -0.177 & 0.020 & -0.186 \\
Consent anxiety & REALM & 0.172 & 0.023 & 0.181 \\
& Type of consent form & -0.178 & 0.008 & -0.212 \\
& State anxiety & 0.174 & 0.029 & 0.177 \\
& Self-efficacy & -0.240 & 0.001 & -0.255 \\
& Perceived barriers & 0.202 & 0.003 & 0.240 \\
Satisfaction & REALM & -0.188 & 0.008 & -0.215 \\
& Respondent age & -0.165 & 0.016 & -0.195 \\
& Type of consent form & 0.200 & 0.005 & 0.228 \\
& Decisional conflict & 0.226 & 0.003 & 0.241 \\
Decisional conflict & Self-efficacy & 0.183 & 0.020 & 0.187 \\
ISEL-appraisal & -0.205 & 0.009 & -0.210 \\
(Not included) & Perceived barriers & -0.139 & 0.045 & -0.162 \\
\hline
\end{tabular}

Abbreviation: REALM, Rapid Estimate of Adult Literacy in Medicine.

values and expectations. Thus, we felt that giving the study participants sufficient time (ie, 2 weeks) to make their decisions was warranted in the setting of deliberating consent for a prevention trial. It is often standard procedure to allow this longer period of deliberation in prevention trials as opposed to treatment trials.

Lower education and income and belonging to a racial or ethnic minority are major barriers to participation in clinical research studies. ${ }^{24,25}$ In our study, the moderators of White race and higher REALM scores, but not lower state anxiety scores, correlated with better comprehension. While racial and ethnic minorities are currently better represented in cancer treatment trials,${ }^{26}$ they have been less so in most cancer prevention trials. The SELECT study is an important exception, as it reached a minority accrual of $21 \%$ (the trial benefited by a minority recruitment and retention subcommittee and inclusion of a large number of VA medical hospitals with greater populations of African American males). ${ }^{27}$ For our consent study, by approaching and enrolling male veterans through veterans' organizations (such as the American Legion), we were able to achieve a large proportion of minority participants (55\%) with a wider range of literacy levels, reflecting an additional strength of this study. The large minority population allowed for better assessment of cultural sensitivity issues related to research participation. In addition, in contrast to prior studies composed mostly of women of higher socio-economic status, our study subjects were men with more varied educational levels. Lastly, we highlight a novel recruiting method by forming successful collaborations with veterans' organizations, which has relevance with regard to planning and conducting large national disease prevention trials in men.

It could be argued that the goal of increasing the number of subjects actually enrolling (or intending to enroll, in this case) in the SELECT cancer prevention trial (our secondary hypothesis) was not accomplished. Although there was a trend favoring intent to participate by the intervention participants compared to the control participants, this difference was not statistically significant. While increasing accrual to clinical trials is important, we contend that it is even more important that prospective participants are well informed and truly understand the pros and cons of participation and their rights and responsibilities within the study. Only then can they make a truly informed decision that is best for them, according to their personal beliefs, values and expectations. ${ }^{1}$ Both the improved understanding and satisfaction achieved with the modified consent document in this study highlight that these important goals were achieved.

The brief video shown to the modified consent group did not address the study details, but illustrated how several veterans apply their values and beliefs to decision making. While the video may have added to the benefits seen in improving satisfaction and decreasing consent anxiety, we feel that it did not impact comprehension scores, since protocol specifics were addressed only in the consent form. Ideally, a three-arm study could have addressed the impact of the video, but would have imposed additional accrual requirements during the short timeline available. 
A limitation of this study is that it could not be conducted in the real setting of consent for the SELECT prostate cancer prevention trial, as initially planned. Since the SELECT trial closed much earlier than anticipated due to rapid accrual, this study was conducted in a simulated consent setting. All of our study participants were SELECT-eligible men who were instructed to evaluate the consent document as if they could still enroll in this cancer prevention trial. The participants relied only on the consent document and the brief video (for those randomized to the modified consent arm); this allowed for a clearer assessment of the impact of these modifications, without influence from a supplemental verbal explanation. We feel that this is actually a strength of the study, since verbal explanations may vary considerably, depending on enrollment sites and personnel. However, we fully understand and agree that person-to-person interactions between study participant and study investigator or coordinator are an important component of the overall informed consent process, and should be a topic for further research.

\section{Acknowledgments}

The authors gratefully acknowledge the veterans who participated in this study and the Colorado and Arizona American Legion and veterans' organizations for their assistance in recruiting study participants.

This study was supported by grant no R25CA072592 from the National Cancer Institute, Department of Health and Human Services (Raich), and a grant from Pfizer Pharmaceuticals Health Literacy (Bennett).

\section{Disclosure}

The authors declare no conflicts of interest in this work. No significant relationship exists between the authors and the companies/organizations whose products or services may be referenced in this article.

\section{References}

1. Raich PC, Plomer KD, Coyne CA, et al. Literacy, comprehension, and informed consent in clinical research. Cancer Invest. 2001;19(4): 437-445.

2. Joffe S, Cook EF, Cleary PD, et al. Quality of informed consent: A new measure of understanding among research subjects. J Natl Cancer Inst. 2001;93(2):139-147.

3. Daugherty CK. Informed consent, the cancer patient, and phase I clinical trials. Cancer Treat Res. 2000;102:77-89.

4. Williams MV, Parker RM, Baker DW, et al. Inadequate functional health literacy among patients at two public hospitals. JAMA. 1995;274(21): $1677-1682$.

5. Kirsch I, Jungeblut A, Jenkins L, et al. Adult Literacy in America. Washington, D.C.: Department of Education; 1992.
6. Kutner M, Greenburg E, Bae J, et al. A First Look at the Literacy of America's Adults in the 21st Century. Washington, DC: National Center for Education Statistics, Department of Education; 2005.

7. Institute of Medicine. The Unequal Burden of Cancer. Washington, D.C.: National Academy Press; 1999.

8. Comprehensive Working Group on Informed Consent in Cancer Clinical Trials for the National Cancer Institute. Recommendations for the Development of Informed Consent Documents for Cancer Clinical Trials. National Cancer Institute, NIH Publication No. 98-4355; 1998. http://cancerTrails.NCI.gov.

9. Christopher PP, Foti ME, Roy-Bujnowski K, et al. Consent form readability and educational levels of potential participants in mental health research. Psychiatr Serv. 2007;58:227-232.

10. Coyne CA, Xu R, Raich PC, et al. Randomized, controlled trial of an easy- to-read informed consent statement for clinical trial participation: a study of the Eastern Cooperative Oncology Group. J Clin Oncol. 2003;21:836-842.

11. Dolan NC, Ferreira MR, Davis TC, et al. Colorectal cancer screening knowledge, attitudes, and beliefs among Veterans: Does literacy make a difference? J Clin Oncol. 2004;22:2617-2622.

12. Lippman SM, Goodman PJ, Klein EA, et al. Designing the Selenium and Vitamin E Cancer Prevention Trial (SELECT). J Natl Cancer Inst. 2005;97:94-102.

13. Wolf MS, Bennett CL. Local perspective of the impact of the HIPAA privacy rule on research. Cancer. 2006;106:474-479.

14. Davis TC, Long SW, Jackson RI, et al. Rapid estimate of adult literacy in medicine: A shortened screening instrument. Fam Med. 1993;25: 391-395.

15. Spielberger CD. Manual for the State-Trait Anxiety Inventory (STAI). Palo Alto, CA: Consulting Psychologist Press; 1983.

16. O'Connor AM. Validation of a decisional conflict scale. Med Decis Making. 1995;15:25-30.

17. Cohen S, Mermelstein R, Kamarack T, et al. Measuring the functional components of social support. In: Sarason IG, Sarason BR, editors. Social Support: Theory, Research and Applications. Springer: New York, NY: Springer Publishing; 1985: 73-94.

18. Flesch R. The Art of Readable Writing. New York, NY: Harper and Row; 1974.

19. Doak C, Doak L, Root J, et al. Teaching Patients with Low Literacy Skills, 2nd ed. Philadelphia, PA: JB Lippincott Co; 1995.

20. Guidry JJ, Walker VD. Assessing cultural sensitivity in printed cancer materials. Cancer Pract. 1999;7:291-296.

21. Kim SP, Knight SJ, Tomori C, et al. Health literacy and shared decision making for prostate cancer patients with low socioeconomic status. Cancer Invest. 2001;19(7):684-691.

22. Davis TC, Holcombe RF, Berkel HJ, et al. Informed consent for clinical trials. A comparative study of standard versus simplified forms. $J$ Natl Cancer Inst. 1998;90:668-678.

23. Gorin SS, Wang C, Raich PC, et al. Decision making in cancer primary prevention and chemoprevention. Ann Behav Med. 2006;32: 179-187.

24. Advani AS, Atkeson B, Brown CL, et al. Barriers to the participation of African-American patients with cancer in clinical trials: A pilot study. Cancer. 2003;97:1499-1506.

25. Shavers VL, Lynch CF, Burmeister LF, et al. Racial differences in factors that influence the willingness to participate in medial research studies. Ann Epidemiol. 2002;12:248-256.

26. McCaskill-Stevens W, Mckinney MM, Whitman CG, et al. Increasing minority participation in cancer clinical trials: the minority-based community clinical oncology program experience. J Clin Oncol. 2005;23:5247-5254.

27. Lippman SM, Goodman PJ, Klein EA et al. Designing the selenium and vitamin E cancer prevention trial (SELECT). JNCI. 2005;97: 94-102. 


\section{Appendix}

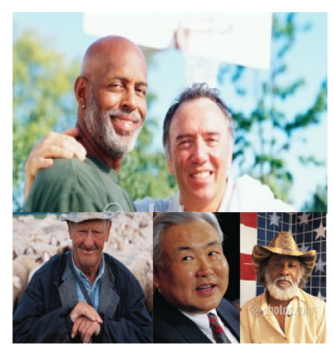

\section{Selenium and Vitamin E Cancer Prevention Irial for Prostate Cancer (SELECT)}

SELECT is a clinical trial (a type of research study). These studies are only for people who want to take part. Take your time to decide. Talk it over with your family, your doctor, or your friends. There are other men who have been in this study. You can talk to them, if you wish.

\section{What am I being asked to do?}

We are asking you to be a part of the SELECT clinical trial. With your help, we can find out if Selenium and vitamin E can prevent prostate cancer. Selenium and vitamin E are what our body needs to stay healthy.

Men age 55 and older and African American men age 50 and older who have never had prostate cancer are being asked to be in this study. (Younger African American men are invited because prostate cancer starts at a younger age in black men).

\section{Who will be asked to be a part of the SELECT Clinical Trial?}

Please circle all the answers you think are true.

I. Men and Women.

2. Men with prostate cancer.

3. Men age 55 and older and African American men age 50 and older who have never had prostate cancer.

Number 3 is the right answer.

\section{Why is this study being done?}

Prostate cancer is the second most common cancer in men in the United States. Skin cancer is number one. One out of 8 men, who live to be older than 80 will get prostate cancer. Most men with prostate cancer do not die of the disease but it can hurt how well you live your life. For example, prostate cancer can cause problems with having sex and going to the bathroom, pain in the bones and low back during bowel movements or during ejaculation.

This study is being done to find out if Selenium or vitamin E can help prevent or lower the chance of getting prostate cancer. No one has ever tried to find out in a large study if Selenium and vitamin E together or alone can prevent prostate cancer. Based on studies of other cancers, we think that using either Selenium or vitamin E can help prevent prostate cancer. How well each one can do this is not known.

The study is also being done to see if taking Selenium or vitamin E might cause any problems or side effects on the body.

What might prevent prostate cancer?
a. Exercise
b. Plenty of sunshine
c. Vitamin BI2
d. Selenium and vitamin E 


\section{Who is doing the study?}

The National Cancer Institute (NCI) is paying for this study. The NCI spends money for all kinds of cancer research in the U.S. The Southwest Oncology Group (a large group of cancer research centers and clinics) will be in charge of the study.

Doctors and researchers at many medical centers in the United States and Canada are part of this study. Drug companies are not paying to help with this study.

\section{How many men will be in the study?}

About 32,400 men from all over the USA, Canada and Puerto Rico will be in this study.

What will happen in the study?

If you join the study, you will take two capsules (like a pill) each day. The kind of capsules you take depends on which group you are put in.

There are 4 groups in the study. The group you are put in is chosen by chance (like tossing a coin). This is called "randomization". A computer decides which group you are put into.

This is how the four groups are set up

\begin{tabular}{|c|c|c|c|c|}
\hline $\begin{array}{l}\text { Men in } \\
\text { GROUP I }\end{array}$ & & $\begin{array}{l}\text { Men in } \\
\text { GROUP } 2\end{array}$ & $\begin{array}{l}\text { Men in } \\
\text { GROUP } 3\end{array}$ & $\begin{array}{l}\text { Men in } \\
\text { GROUP } 4\end{array}$ \\
\hline Will get a & $=8$ & Will get a & Will get a & Will get placebo capsules only \\
\hline Selenium capsule & $\begin{array}{c}3=5 \\
20\end{array}$ & Vitamin E capsule & Selenium capsule & (“Placebo" capsules have $\mathrm{NO}$ \\
\hline+ & $=0$ & + & + & Selenium or vitamin $E$ in them) \\
\hline Placebo capsule & & Placebo capsule & Vitamin E capsule & + \\
\hline+ & & + & + & \\
\hline
\end{tabular}

You and your doctor will not know which group you are in until the end of the study.

Researchers feel that doing a study in this way and using a placebo is the best way to find out if the idea really works or does not work.

Question: Can you decide which of the four groups you will be in?

(Please circle the answer you think is correct) Yes or No

Answer: You will be put into one of the four groups, but you will not know which one until the study is over.

"No" is the right answer.

\section{How long will I be in the study?}

You will be asked to be in the SELECT study for $\mathbf{7}$ to 12 years, depending on when you start. We think it will take this long to see if Selenium or vitamin E can prevent prostate cancer.

\section{How will my health be watched during the study?}

In the beginning, you will be asked to give a blood sample and some toenail clippings to see how much Selenium and vitamin E is already in your body. You can tell us if you want to have your samples saved for future research by checking the boxes at the end of this form.

In the first year, you will be called by telephone at 3 months and again at 9 months after you start the study to see how you are doing. 
We want you to come into the clinic (with your capsules) for a visit every 6 months. At these visits, you will be asked how you are doing. We will also count the capsules you bring in.

\section{Working with your doctor and the SELECT staff}

Every year, your doctor will give you a medical check-up. During this visit, you may choose to have a prostate exam (digital rectal exam) and a blood test to look for signs of prostate cancer. The blood test will see how much PSA or prostate specific antigen is in your blood. You should talk to your doctor about these tests. It is up to YOU to decide if you want them done or not. Some men (about 1 in 10) also will be asked for an extra blood sample each year.

During this study, your doctor may find out that you have to have surgery or a biopsy on your prostate. A biopsy is a way to remove a small part of the prostate to check for cancer. If it looks like your prostate tissue may have cancer, the samples will be sent to a SELECT office to make sure.

Both your doctor and the study staff can talk to you about this study. If you decide to take part in the study they will see you or talk to you every 6 months during the study. You may call them at any other time. They will work together to make sure that you get the right check-ups.

We want you to tell us about your quality of life (how you feel) during this study. We say this because we are trying to find out how to prevent cancer in men who are already healthy rather than treat a disease.

Before you start the study you will be asked some questions and also asked to fill out forms to explain how you feel. By filling out these forms, you will help describe the effects of this study on your quality of life.

We want you to do this several times starting with your first visit, then after three years, five years, and seven years. We want to see if how you feel changes over time.

The chart below is to help you see what will happen during the time you are in the study.

During your first year in the study
In the first month you will have your first clinic visit
(A blood sample and toenail clippings will be taken)
After 3 months someone from the clinic will call to see how you are doing
After 6 months you will come to the doctor's office for a check-up
After 9 months someone from the clinic will call to see how you are doing
After 12 months you will come to the doctor's office for a check-up
(Some men will be asked for a blood sample)
For the rest of your time in the study (years 2-I2)
We need you to make an office visit every 6-months
You will get a medical check-up every year from your doctor
(Some men will be asked for a blood sample)

\section{Will I have to change what I eat while I am on the study?}

No. You will not have to change what you eat. But, we ask that you stop taking any vitamins with Selenium or vitamin E. A special multi-vitamin with no Selenium or vitamin E will be given to you at no charge while you are in the study.

Question: Will I be able to take vitamins with Selenium or vitamin E?

Yes or No

Answer: We ask that you do not take any vitamins containing Selenium or vitamin E. A special multi-vitamin with no Selenium or vitamin E will be given to you at no charge while you are in the study.

"No" is the right answer.

\section{What are my risks in joining the study?}

Some minor side effects are possible. They are listed on the next two pages. There may be other side effects that we do not know about. Most side effects go away soon after the capsules are stopped. 


\section{Selenium}

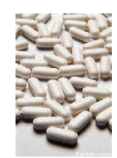

What are the risks from Selenium?

No serious side effects have been seen with amounts or doses used in this study.

Taking higher doses of selenium for longer periods of time could cause:

Upset stomach

Bad breath (like garlic)

Changes in hair or nails (brittle, can break off easily)

Cough (like a cold)

Runny nose (like a cold)

Feeling dizzy weak or tired

Feeling cranky

Skin redness or rash

\section{Vitamin E}

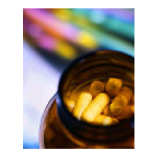

What are the risks from Vitamin E?

No serious side effects have been seen with amounts or doses used in this study.

One study reported that men, who smoked and had high blood pressure that wasn't under control, were more likely to have a stroke than other men in the study.

\section{Placebo}

(A "placebo" is a capsule with no drugs in it. They are often called "sugar pills")

What are the risks from a placebo?

There are few to no side effects to taking a placebo.

These pills are okay for people who have diabetes.

Please let your doctor know if you have trouble taking anything with soybean in it.

\section{Selenium + Vitamin E (together)}

\section{What are the risks from taking both?}

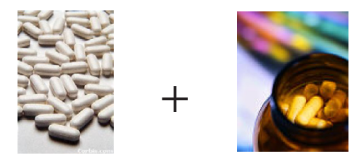

Based on what we know from past studies, the effects of taking Selenium and vitamin E together is no different from what could happen if you take Selenium or vitamin E alone.

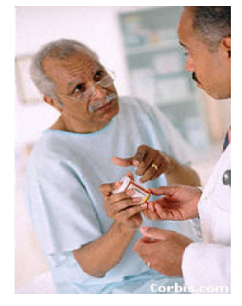

Be sure to tell your doctor about any side effects or problems you may have while you are on the study. 


\section{Giving blood samples, tissue samples and toenail clippings:}

\section{What are the risks?}

There are few risks when you give samples of your blood and toenail clippings.

Prostate tissue is taken through a process called biopsy. You would have a prostate biopsy only if your doctor thinks you need one. Having a biopsy is not a part of this study. Your doctor will explain the reasons and risks if he/she thinks a biopsy is needed.

Drawing blood could cause minor pain and might leave a bruise that will soon go away.

Information about these blood and toenail samples will not show up in your health records or doctor's charts.

There is a very small chance that information from your study records could hurt if you apply for insurance or jobs. The Southwest Oncology Group is in charge of making sure that this will not happen.

\section{Question: Should you expect to have side effects during this study?}

Yes or No

Answer: You will probably not have side effects from the study vitamins. Side effects have been seen only at higher doses and over longer periods of time.

No, is the right answer.

\section{What will I get out of being in the study?}

There may be no direct benefit to you for being part of this study. The reason for the study is to find out if Selenium and vitamin $\mathrm{E}$, taken alone or together, can prevent prostate cancer. What we learn in this study may be useful to men in the future. You will not be paid for taking part in this study.

Question: Can you be sure that you will get a personal benefit from being in this study?

Yes or No

Answer: The study vitamins may or may not stop prostate cancer in you.

\section{What other options do I have?}

You may choose to be in other studies that are looking at ways to stop prostate cancer.

Please talk to you doctor about this and any other choices to help stop prostate cancer.

No one knows for sure how to stop prostate cancer.

\section{How will my privacy be protected?}

Records about you, like the results of your blood tests, will be kept private. It will only be used for research. Your personal records will only be made known to others as needed by law. Your name will not be used in any written reports or articles about this study.

\section{These are some people who will be able to look at or copy your study records:}

The National Cancer Institute (NCI).

The Food and Drug Administration (FDA).

The companies who provide the Selenium, vitamin E, and placebo capsules.

The Southwest Oncology Group.

The Institutional Review Board (IRB) (a group of people who protect your rights).

\section{What are the costs for being in this study?}

There will be no cost to you for any of the treatment, testing, or storage of records as a part of this research study. There is no added cost to you for the study capsules of Selenium, vitamin E, or multivitamins. 


\section{What happens if I get sick or hurt as a result of the study?}

The VA Medical Center will provide medical care and treatment for any injury that is a result of taking part in this study. Some federal laws or other rules may permit payment for such an injury. In order for this policy to remain in effect, you must comply with the study directions.

\section{Can I be taken off the study for any reason?}

The researcher may decide to take you off the study if:

You get prostate cancer.

The side effects of Selenium or vitamin E are too much for you to handle.

You stop coming in for visits on your own.

New facts become known that would be reason to stop the study.

Not enough Selenium or vitamin E capsules are made.

There is not enough money for the study.

\section{What are my rights if I decide to be a part of this study?}

Taking part in the study is your choice. You may decide not to take part. Your medical care will not be at risk if you choose not to take part.

You may quit being in the study at any time. If you quit the study, you will not lose any of your health insurance. We ask that you talk to your doctor or the person in charge of the study before you decide to leave the study.

You may be part of the SELECT study without giving blood, toenail and tissue samples to be stored for future research.

You can also change your mind about having your blood, toenail and tissue samples stored. If you change your mind, the samples will be destroyed. We need you to tell us in writing to have this done.

None of your decisions will affect your care.

We will tell you about any changes in the study that affect you.

At the end of the study, you will be told which group you were in.

When the study is over, you will be told if Selenium, vitamin E, or neither was able to stop prostate cancer.

\section{Question: Can you quit this study before it is done? Yes No}

You can leave the study at any time. If you decide to quit, we urge you to talk to your doctor, or study coordinator first.

Yes, is the right answer.

\section{Who can I call with questions or problems?}

For questions about the study, or if you get sick or are hurt as part of this study, call the research doctor

[Site PI name]

\section{at [telephone number].}

For questions about your rights while you are in this study, call the Coordinator of the

Institutional Review Board (a group of people who protect your rights) at

[telephone number].

\section{Where can I get more information?}

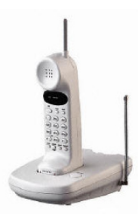

For more information on prostate cancer, in the United States and Puerto Rico call the NCI's Cancer Information Service (CIS) at 1-800-4-CANCER (1-800-422-6237) or 1-800-332-8615 if you have a hearingdisabled TTY telephone).

For more information on clinical trials and cancer, visit Internet websites:

CancerTrials: Complete information about clinical research studies

(National Cancer Institute) http://cancertrials.nci.nih.gov .

CancerNet ${ }^{\mathrm{TM}}$ : Useful information about current cancer prevention, detection and treatment (National Cancer Institute) http://cancernet.nci.nih.gov.

American Cancer Society: Practical information about cancer prevention, detection and treatment http://www.cancer.org 
What does signing this consent form mean?

Signing this consent form means you decided to be part of the SELECT study.

It means you have read the consent form and that you know what will happen in the study.

A copy of this informed consent will be given to you after you sign it.

If you decide not to take part in the study, just give the unsigned form back to the doctor, nurse, or study coordinator.

\section{Patient Consent to Participate in the Selenium and Vitamin E Prostate Cancer Prevention Trial (SELECT)}

I have:

$\square \quad$ Read all of the above information.

$\square \quad$ Asked questions.

$\square$ Received answers about areas I needed more information about.

I willingly give my consent to take part in this study.

I will receive a copy of this form after I sign it.

Patient signature

Signature of person obtaining consent
Date

Date

Physician signature

Date

\section{Special Consent to Participate in the Selenium and Vitamin E Prostate Cancer Prevention Trial (SELECT) Contact Database Project}

We would like to keep your name and address, and a telephone number or FAX number in a computer file with other men in the SELECT study. This will allow us to make address labels in order to send you information in the mail about the study. Only people at the SELECT study offices in Seattle, Washington and San Antonio, Texas will use your information.

Your address will only be used to send mail about the study you are taking part in. Your address information will not be rented, sold or made available to any person or group outside of the SELECT study.

You do not have to give your name and address as part of your taking part in the SELECT study. If you do not want to be in this file, your study coordinator will tell you about any changes in the study.

All of your study records will be kept private. When the study is written up for reporting, your name will not be used.

I agree to take part in the Contact Data Base Project.

(Please circle your choice and initial).

YES NO Your Initials:

Patient signature

Date

Signature of person obtaining consent

Date 


\section{U.J Special Consent to Use Blood, Toenail Clippings, and Prostate Tissue For future studies}

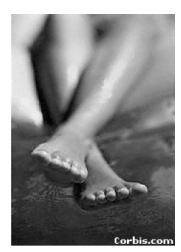

Blood samples, toenail clippings, and possibly prostate tissue (if you have a biopsy) will be taken from you if choose to join the SELECT trial. We need special permission from you to store and use the blood, toenail clippings, and prostate tissue not needed for the SELECT study. These samples may be used for future research.

You can still be part of the Selenium and vitamin E Cancer Prevention Trial if you choose not to let us store and use these samples.

What will happen if I agree to let you use my extra blood, toenail clippings, and prostate tissue?

The extra blood, toenail clippings, and prostate tissue you give as part of the SELECT study will be stored and may be used for other (such as genetic) research. Some of this research is related to this study and some is not.

Genetic studies are very complex. They require many cells to explore how genes may affect the risk of prostate cancer. A small amount of your white blood cells may be "grown" to make a "cell line" (more cells) that can be used in this research.

Some researchers may want to use your samples for genetic research. You will have a chance to decide for what type of research, if any, you will allow your samples to be used.

\section{What are the risks?}

The greatest risk to you is that sample results could be seen by someone other than your doctor (for example, if you apply for health insurance or jobs). This would be very rare, because the results of the samples will not have your name on them.

\section{What are the benefits?}

There is no direct benefit to you.

Using blood, toenails and tissue will help researchers learn more about what causes cancer and other diseases. The samples may help researchers learn how to prevent, treat, and cure these diseases.

\section{How will my privacy be protected?}

Your personal information (your name, address, telephone number) will be removed from the samples you give before they are given to the researcher.

Your blood, toenail clippings, and tissue samples will have a special code. This will make it very hard for anything about the study to be linked to you or your family.

Results from what is done with your blood, toenail clippings, and tissue will not be given to you or your doctor. These reports will not be put in your health record or doctor's chart.

The research will have no effect on your health care.

\section{What is the cost?}

There is no charge to you to store your blood, toenail clippings, and tissue.

You will not be paid for giving these samples.

\section{What are my rights as a study participant?}

It is your choice to allow researchers to use your extra blood samples, toenail clippings and prostate tissue for other research.

You can change your mind at any time. Changing your mind will not result in any loss of your health benefits. 


\section{Who can I call with questions or problems?}

For questions, or if you get sick or are hurt from giving these samples, call the research doctor

[Site PI name] at [telephone number].

For questions about your rights as a study participant, call the Coordinator of the [name of institution] Institutional Review Board (a group of people who protect your rights) at [telephone number].

\section{What does signing this consent form mean?}

Signing this consent form means you have read the consent form and that you know what this part of the study is about.

A copy of this informed consent will be given to you after you sign it.

\section{Patient Special Consent \\ Blood, Toenail Clippings, and Prostate Tissue for Future Studies}

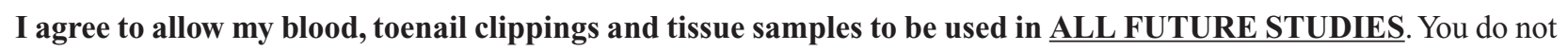
have to contact me again in the future for this consent. I understand that my samples may be used in genetic research and research that is not related to the SELECT study.

YES NO Your initials:

Or:

I agree (YES) or don't agree (NO) to the following: (Please circle your answer)

I agree to allow my blood, toenail clippings and tissue samples to be used in

$\underline{\text { Research related to this study. }}$

YES NO Your initials:

I agree to allow my blood, toenail clippings and tissue samples to be used in

Research not related to this study.

YES NO Your initials:

I agree To be contacted in the future to be asked to give consent for my blood, toenail clippings and tissue specimens to be used for genetic research.

YES NO Your initials:

I have read all of the above information, asked questions and received answers about areas I didn't understand. I agree to allow my samples to be used for the studies I checked and wrote my initials above.

Patient signature

Date

Witness

Date

Doctor signature

Date

Patient Intelligence

\section{Publish your work in this journal}

Patient Intelligence is an international, peer-reviewed, open access journal that characterizes and measures the central role of patient behavior and intention in optimizing healthcare management in all areas of disease and complaint types. An improved understanding of patient intelligence coupled with predictive analysis helps an organization contribute more effectively to achieving better outcomes.

Submit your manuscript here: http://www.dovepress.com/patient-intelligence-journal
The journal is characterized by the rapid reporting of reviews, original research, methodologies, analytics, modeling, clinical studies and patient surveys across all disease areas. The manuscript management system is completely online and includes a very quick and fair peer-review system. Visit http://www.dovepress.com/ testimonials.php to read real quotes from published authors. 